\title{
Androgen Regulation of Rat Renal Angiotensinogen Messenger RNA Expression
}

Kristin E. Ellison, Julie R. Ingelfinger, Mitchell Pivor, and Victor J. Dzau

Molecular and Cellular Vascular Research Laboratory, Brigham and Women's Hospital, and Division of Nephrology,

The Children's Hospital, Boston, Massachusetts 02115

\begin{abstract}
Renal angiotensinogen (ang-n) mRNA concentration in the male WKY rat increases significantly during puberty. Furthermore, renal angiotensinogen mRNA level in the adult female WKY rat is considerably lower than in the male. The present study investigates the role of androgen in differential renal ang-n mRNA expression. Northern and slot blot analyses with $\alpha-{ }^{32}$ P labeled ang-n cDNA (pRang 3) demonstrated that castration lowered ang-n mRNA levels in the male kidney by $\geq 60 \%$ compared with control, suggesting that androgen may be involved with renal ang-n gene regulation. Moreover, male WKY rats castrated as weanlings and normal adult female WKY rats each implanted with testosterone displayed significant $(P<0.05)$ increases in renal ang-n mRNA levels. Our observations, taken together with previous reports that androgen influences proximal tubule morphology and the tubular expression of transport proteins (e.g., $\mathrm{Na}^{+} / \mathrm{H}^{+}$antiporter), may have important physiological implications for understanding the relationship between androgen and angiotensin in the regulation of tubular function.
\end{abstract}

\section{Introduction}

Angiotensinogen is synthesized in many extrahepatic tissues including the kidney (1). It has been proposed that the locally generated angiotensin may contribute directly to the regulation of local tissue functions $(2,3)$. In a previous study we demonstrated that renal angiotensinogen (ang-n) ${ }^{1}$ mRNA expression is regulated by sodium (4). An in situ hybridization study performed in our laboratory localized renal angiotensinogen mRNA to the proximal convoluted tubule and the intrarenal vasculature (5), providing evidence for a complete renin angiotensin system within the kidney and suggesting a possible physiologic role for local angiotensin in the proximal tubule. In the present study we investigated renal angiotensinogen mRNA expression in both adult male and female WKY rats and also in immature male and female rats during their growth and development. We studied further the role of androgen in renal angiotensinogen expression by examining the effects of castration followed by testosterone replacement in

Address reprint requests to Dr. J. R. Ingelfinger and Dr. V. J. Dzau, Molecular and Cellular Vascular Research Laboratory, Brigham and Women's Hospital, 75 Francis Street, Boston, MA 02115.

Received for publication 16 June 1988 and in revised form 24 January 1989.

1. Abbreviations used in this paper: ang-n, renal angiotensinogen.

J. Clin. Invest.

(c) The American Society for Clinical Investigation, Inc.

0021-9738/89/06/1941/05 \$2.00

Volume 83, June 1989, 1941-1945 the adult male rat. In addition, the testosterone effect on female rat renal ang-n mRNA level was examined.

\section{Methods}

\section{Animals}

All WKY rats studied were obtained from Charles River Breeding Laboratories (North Wilmington, MA). The following protocols were performed.

Study of adult male versus female rats. WKY male and female rats (aged $12 \mathrm{wk}$ ) were studied in the baseline state on a normal diet (Purina Lab Chow) with free access to water.

Testosterone replacement of castrated male rats. Male rats castrated as weanlings and raised to maturity were used for testosterone replacement studies. 50-mg pellets (Innovative Research, Toledo, $\mathrm{OH}$ ) designed to release $2.5 \mathrm{mg} / \mathrm{d}$ of testosterone $(n=4)$ or vehicle $(n=4)$ were implanted for $20 \mathrm{~d}$, after which time animals were studied. Weights and blood pressure were similar at death in all animals.

Testosterone treatment of female WKY rats. Adult female WKY rats were treated with testosterone $(n=6)$ or vehicle $(n=6)$ in the form of slow-releasing pellets for $20 \mathrm{~d}$ as above. Note that in animals treated with testosterone, blood pressure was similar in control and treated animals, as were weights at death.

Developmental study of male versus female rats. WKY male and female rats were studied at day 35 (prepubertal), day 63 (pubertal) and day 91 (adult). At least five animals of each sex were studied at each developmental age and sex.

Rats were killed by decapitation. Blood was collected in chilled, EDTA-containing tubes for subsequent plasma renin radioimmunoassay. Organs were snap-frozen in liquid nitrogen within $3 \mathrm{~min}$. Kidneys were sagittally bisected prior to freezing. All tissue was stored at $-80^{\circ} \mathrm{C}$ until used.

\section{RNA studies}

Homogenization of various tissues was carried out in $4 \mathrm{M}$ guanidine thiocyanate, $0.5 \%$ sodium- $n$-lauryl sarcosine, $25 \mathrm{mM}$ sodium citrate, $0.1 \mathrm{M} \beta$-mercaptoethanol and $2 \mathrm{M} \mathrm{CsCl}$ (6). Anglerfish islet cell mRNA was added to the homogenate ( $1 \mu \mathrm{g}$ RNA/g of tissue) as a recovery marker $(7,8)$. The homogenate was applied over a cushion of autoclaved $5.7 \mathrm{M} \mathrm{CsCl}, 25 \mathrm{mM}$ sodium acetate, $\mathrm{pH} 5.5$, and the RNA pelleted by centrifugation at $35,000 \mathrm{rpm}\left(8.4 \times 10^{4} \mathrm{~g}\right)$ for $16 \mathrm{~h}$ at $20^{\circ}$ in a Ti 70.1 fixed angle rotor (Beckman Instruments, Inc., Fullerton, CA). The RNA was resuspended in $0.2 \mathrm{M}$ sodium acetate, $\mathrm{pH} 5.5$, rocked at $4^{\circ} \mathrm{C}$ for $1 \mathrm{~h}$, and precipitated in $2 \mathrm{vol}$ of ethanol. The precipitated RNA was dissolved in water and the amount quantitated by absorbance at $260 \mathrm{~nm}$. Comparison of relative mRNA levels were made in reference to same amount of total RNA applied per sample. Efficiency of transfer was confirmed by ethidium bromide stain and examined preand posttransfer. Anglerfish islet cell insulin RNA, added as an exogenous probe ( $1 \mu \mathrm{g} / \mathrm{g}$ of tissue), revealed similar recoveries in our samples (8).

RNA was lyophilized and denatured with glyoxal in a denaturing mixture consisting of $1.2 \mathrm{M}$ glyoxal, $50 \%$ ( $\mathrm{vol} / \mathrm{vol}$ ) dimethyl sulfoxide, and $0.01 \mathrm{M} \mathrm{NaH}_{2} \mathrm{PO}_{4}, \mathrm{pH}$ 6.5. Denatured samples were size-separated by electrophoresis on $1.5 \%$ agarose gels at $80 \mathrm{~mA}$ for $4 \mathrm{~h}$ in constantly recirculating $0.01 \mathrm{M}$ phosphate buffer, $\mathrm{pH}$ 6.5. A Hind III digest of bacteriophage lambda was run as a molecular weight marker. 
Gels were transblotted to nylon filters by capillary action with $15 \times$ SSC for $20 \mathrm{~h}$, after which they were baked at $80^{\circ} \mathrm{C}$ in a vacuum oven for $2 \mathrm{~h}$. A solution of $50 \%$ formamide, $5 \times$ Denhardt's solution, 25 $\mu \mathrm{g} / \mathrm{ml}$ yeast tRNA, $25 \mu \mathrm{g} / \mathrm{ml}$ salmon sperm DNA, poly A RNA 10 $\mu \mathrm{g} / \mathrm{ml}$, poly C RNA $10 \mu \mathrm{g} / \mathrm{ml}$ in $0.2 \%$ SDS was used for prehybridizing blots for 3-4 h. The blots were then hybridized overnight in the same buffer to which $\alpha^{32} \mathrm{P}$ cDNA was added. For additional quantitative studies, we performed slot blot hybridization analysis. Samples were formaldehyde denatured (9) and then serially diluted in 15× SSC. Three concentrations from each sample $(8,4$, and $2 \mu \mathrm{g})$ were blotted in duplicate to nylon filters using a slot blot apparatus (Schleicher \& Schuell, Peterborough, NH) after which blots were hybridized as above.

After hybridization, blots were washed in $0.2 \times$ SSC with $0.1 \%$ SDS sulfate at room temperature for $20 \mathrm{~min}$, then three times at $65^{\circ} \mathrm{C}$ for 30 min. Blots were exposed to x-ray film (Kodak XAR; Eastman Kodak, Rochester, NY). Autoradiographs were scanned with microdensitometer (LKB, Paramus, NJ). The relative levels of the signal from each sample (run in duplicate) were estimated from concentrations of total RNA and corrected by the anglerfish islet cell insulin mRNA recovery signal. Standard RNA samples from adult male liver and kidney ( 25 and $50 \mu \mathrm{g}$, respectively) were run on all blots as interblot reference standards to normalize calculations. Our intrablot and interblot coefficient of variation are $9 \%$ and $10 \%$, respectively.

Angiotensinogen cDNA (pRang 3 ) is a partial length rat liver angiotensinogen cDNA cloned by Lynch et al. into the Bam $\mathrm{H} 1$ site of PUC 9 (10). Nucleotide sequence analysis revealed that this cDNA consists of nucleotides 650 to 1140 of rat angiotensinogen cDNA. This probe was initially used for protocol 1 . Subsequent studies were performed with a full length rat liver angiotensinogen probe (pRang 1650) also cloned by Lynch et al. (11). For renin mRNA determinations we used renin cDNA pDD 1D-2, a full length mouse submaxillary gland renin cDNA cloned by Field et al. (12). As a control probe we used ${ }^{32} \mathrm{P}$ cDNA to anglerfish islet cell insulin $(7,8)$.

\section{Radioimmunoassays}

Plasma renin concentration assay is performed with rat plasma obtained from blood collected in ice chilled tubes containing sodium EDTA (final concentration of $4 \mathrm{mM}$ ). Plasma is incubated with excess exogenous substrate at $37^{\circ} \mathrm{C}, \mathrm{pH} 7.4$ with protease inhibitors $(3.4 \mathrm{mM}$ 8-hydroxyquinolone sulfate, $0.25 \mathrm{mM}$ EDTA, $0.1 \mathrm{mM}$ PMSF, $1.6 \mathrm{mM}$ dimercaprol and $5 \mathrm{~mm}$ sodium tetrathionate) for $1-3 \mathrm{~h}$. The source of substrate is diluted (1:3) plasma from sheep nephrectomized $48 \mathrm{~h}$ before plasma collection. The angiotensin I generated is measured by radioimmunoassay (13).

Tissue renin concentration is similarly determined. The tissue is homogenized in $0.1 \mathrm{M}$ Tris $\mathrm{HCl}$ pH 7.4 containing the above inhibitors plus $0.1 \%$ Triton $\mathrm{X}-100$. After centrifugation to remove debris, the supernatant is assayed as above. Tissue protein concentration is determined by the method of Bradford (14). Plasma angiotensinogen concentration was determined as previously described (15). Serum testosterone was determined in representative animals using an RSL kit (Radioassay Systems Laboratories, Inc., Carson, CA) (16).

\section{Statistics and quantification of $m R N A$}

Autoradiograms generated by slot blots were scanned with a microdensitometer with background set to zero for each autoradiograph. Regression lines were calculated from the integral values obtained by scanning each sample at the serial concentrations of RNA applied to the blot for each. The relative signals of the specific mRNA were estimated from the slope of the regression line, and only $r$ values $\geq 0.90$ were accepted. Slopes of specific mRNA for each condition (e.g., control vs. testosterone) or for each age group (e.g., day 35 vs. day 91) were compared as relative ratios. In our hands $\geq 90 \%$ of our applied samples satisfied these criteria. Sufficient material was available to study specimens with multiple sample applications. Average slopes were directly compared by Student $t$ tests for studies in adult animals. In developmental studies we also performed $t$ tests on the logarithms of

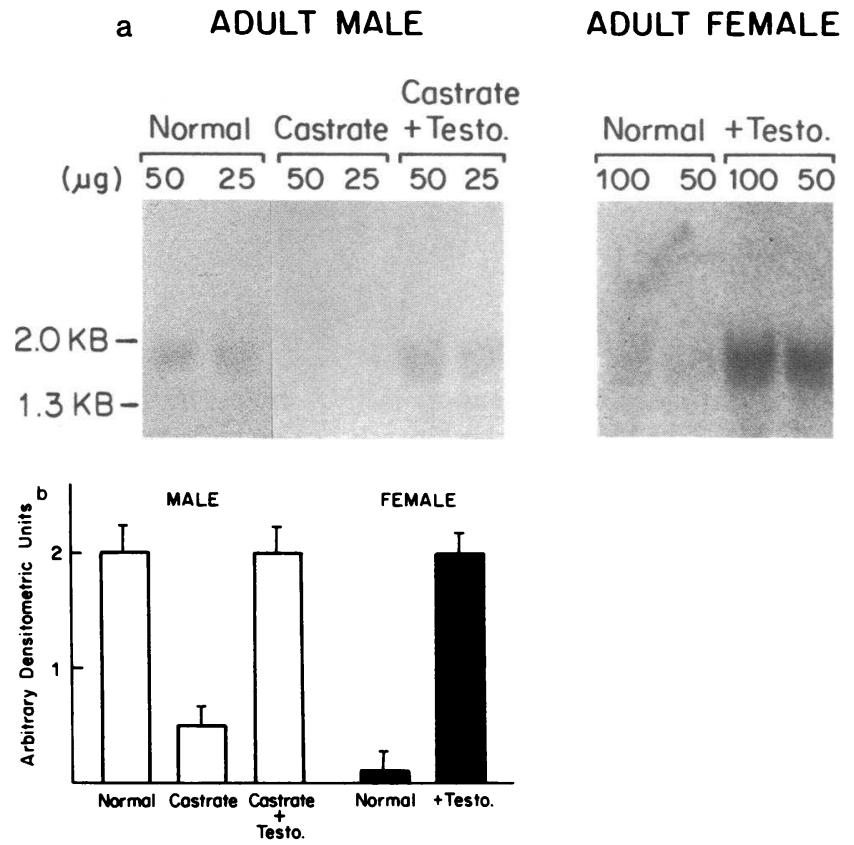

Figure 1. (a) Representative Northern analysis of adult WKY male and female renal angiotensinogen mRNA. 25 and $50 \mu \mathrm{g}$ of total RNA were applied to gels for male, and 50 and $100 \mu \mathrm{g}$ for female. Note that adult male kidney mRNA signal is high and greatly attenuated with castration. Testosterone administration to castrated male animals restores renal angiotensinogen mRNA signal. In adult female animals, renal angiotensinogen mRNA level is low, but is induced by testosterone administration. Male and female blots were run separately and had differing exposure times, $48 \mathrm{~h}$ for male, 96 for female to allow detection. Direct comparison of male and female blots is not intended. For a quantitative comparison of angiotensinogen mRNA levels between male and female animals, we performed slot blot analysis as shown in b. (b) Quantitative analysis of angiotensinogen mRNA of adult WKY male and female kidneys using slot blot analysis. These blots were simultaneously hybridized and exposed for the same time. Densitometric analysis of slot blots was performed on the above groups. Three levels of RNA were applied to slot blots, which were then hybridized to $\alpha^{32} \mathrm{P}$ cDNA for angiotensinogen. Slopes were then generated by tracing autoradiographic signals using an LKB densitometer. Units are arbitrary densitometric units. $* P<0.05$.

these observed ratios, e.g., day 35 cf. to day 91 , and compared to the logarithm of an expected ratio of equality $(\log 1=0)(4)$. To control for possible sample variability, identical slot blots were performed and hybridized with the control anglerfish islet cell cDNA probe.

\section{Results}

Total RNA extracted from adult WKY rat kidneys was hybridized with $\alpha^{32} \mathrm{P}$ angiotensinogen cDNA and subjected to Northern blotting or to slot blot analyses. As mentioned in methods section, the recovery of RNA was monitored in all samples. Anglerfish insulin mRNA levels were comparable in all samples (data not shown). Our results demonstrated that while adult male rat kidney exhibited a high signal for angiotensinogen mRNA, female rat kidney showed very low signals as shown in a representative Northern blot (Fig. $1 a$ ). To study this phenomenon further, adult male rats were castrated as 
Table I. Liver mRNA in Testosterone vs. Control or Castrated Animals

Nope (arbitrary
$\begin{gathered}\text { densitometric units) } \\ \text { Castrate male }\end{gathered}$

The relative slopes under the noted conditions. Testosterone replacement as administration was for $20 \mathrm{~d}$.

weanlings and raised to adulthood. At killing, the renal angiotensinogen mRNA level had diminished to female level as shown in a representative Northern blot in Fig. $1 a$. When such male castrates were treated for $20 \mathrm{~d}$ with testosterone pellets designed to release $2.5 \mathrm{mg} / \mathrm{d}$ for $21 \mathrm{~d}(n=5)$, the level of renal angiotensinogen mRNA increased dramatically (Fig. $1 a$ ). To investigate whether androgen is able to increase angiotensinogen mRNA levels in adult female rats, six rats were implanted with slow releasing 50-mg pellets of testosterone (releasing 2.5 $\mathrm{mg} / \mathrm{d}$ ) for $20 \mathrm{~d}$. These animals responded with a marked increase in renal angiotensinogen mRNA levels as compared to control adult female rats $(n=6)$ given vehicle pellets (Fig. $1 a$ ). In these animals, blood pressure and weights were similar in control and testosterone-treated animals.

To quantitate the above findings, multiple slot blots were performed for each of the conditions demonstrated on Northern analysis as shown in Fig. $1 b$. In the adult male WKY, renal angiotensinogen mRNA level decreased by $60 \%$ as a result of castration $(P<0.05)$ and was restored by testosterone administration (columns 1-3). Normal adult female kidney expressed extremely low renal angiotensinogen mRNA level, which was difficult to quantify due to the small amount of detectable signal. However, androgen administration induced a level of expression in the kidney that was comparable to that of the adult male (Fig. $1 b$ ). Liver angiotensinogen mRNA increased with testosterone treatment also, as shown in Table I. However, the magnitude of increase was far less than in kidney.

Renal angiotensinogen mRNA expression was also examined during ontogeny in the male and female WKY rat. Total RNA extracted from WKY rat kidney of developing males and females at prepubertal (day 35), pubertal (day 63), and postpubertal (day 91) ages was hybridized with $\alpha^{32} \mathrm{P}$ angiotensinogen pRang 3. On Northern analysis, angiotensinogen mRNA expression appeared to be very low in male kidney before puberty, at which time the level increased markedly and remained so into adulthood (Fig. 2). In contrast, female kidney expression of angiotensinogen mRNA was low at all ages examined (Fig. 2 a). An examination of liver angiotensinogen mRNA expression in both male and female rats of the same ages revealed that levels of expression were fairly constant during ontogeny. Furthermore, no evident difference was observed between the two sexes (Fig. $2 a$ ).

Quantitative analysis of these developmental studies was performed using slot blot analysis (Fig. $2 b$ ) followed by densitometry. In the male, the very low level of prepubertal renal angiotensinogen mRNA expression increased 10-fold at puberty $(P<0.1)$ and remained elevated at day 91 . Normal female levels for renal angiotensinogen mRNA were very low throughout ontogeny and this precluded accurate analysis. In contrast to renal angiotensinogen mRNA expression, liver levels of angiotensinogen mRNA were not significantly different at various ages studied $(P=\mathrm{NS})$.

To compare angiotensinogen expression with another component of the renin angiotensin system during ontogeny, renin mRNA levels were determined in kidney in all animals studied. In contrast to angiotensinogen, renal renin mRNA levels remained constant throughout development in both male and female rats, as shown in a representative Northern blot (Fig. $2 a$ ). Densitometric analysis of slot blots for renal renin mRNA during ontogeny are shown in Fig. $2 b$ and do not reveal significant differences for the various ages studied. Radioimmunoassays showed no marked differences in plasma renin activity or plasma substrate level during development in males or females. These levels did not change with testosterone treatment (Table II). Serum testosterone levels showed that male levels dropped to female with castration $(100-150 \mu \mathrm{g} / \mathrm{dl}$ in normal male; $2-7 \mu \mathrm{g} / \mathrm{dl}$ in normal female and castrate male). Levels in pellet treated animals exceeded that of normal male. Kidney renin concentration was also uninfluenced by the age of animals or by testosterone treatment.

\section{Discussion}

In the present study we found a sexual dimorphic expression of renal angiotensinogen mRNA. This difference appears to be androgen dependent based on the following observations: $(a)$ the prepubertal as compared to adult male rat kidney contains significantly lower angiotensinogen mRNA level; the mRNA concentration reached adult level upon puberty; $(b)$ the angiotensinogen mRNA level in the female kidney remain low throughout ontogeny and into adulthood, and is comparable to the level in the prepubertal male rat kidney; $(c)$ the castration of the male rat decreased renal angiotensinogen mRNA level; $(d)$ androgen replacement therapy restored renal angiotensinogen mRNA level in the castrated male rat; and $(e)$ testosterone treatment increased renal angiotensinogen mRNA level in the female.

A growing body of data suggests that androgen may affect renal metabolic processes (17-21). For instance, androgen treated female mouse kidney exhibits hypertrophy of renal proximal tubular cells, with increased protein and RNA synthesis (17). Swank et al. reported that androgen induced the synthesis of many renal enzymes, the most significantly being alcohol dehydrogenase $(10 \times)$ and glucuronidase activity $(20-50 \times)(19)$. Watson et al. demonstrated that the induction of glucuronidase activity reflected the synthesis of new enzyme molecules by mouse kidney epithelial cells rather than a change in the stability or activation of preexisting enzyme molecules (17). Schiebler and Danner also observed a direct influ- 

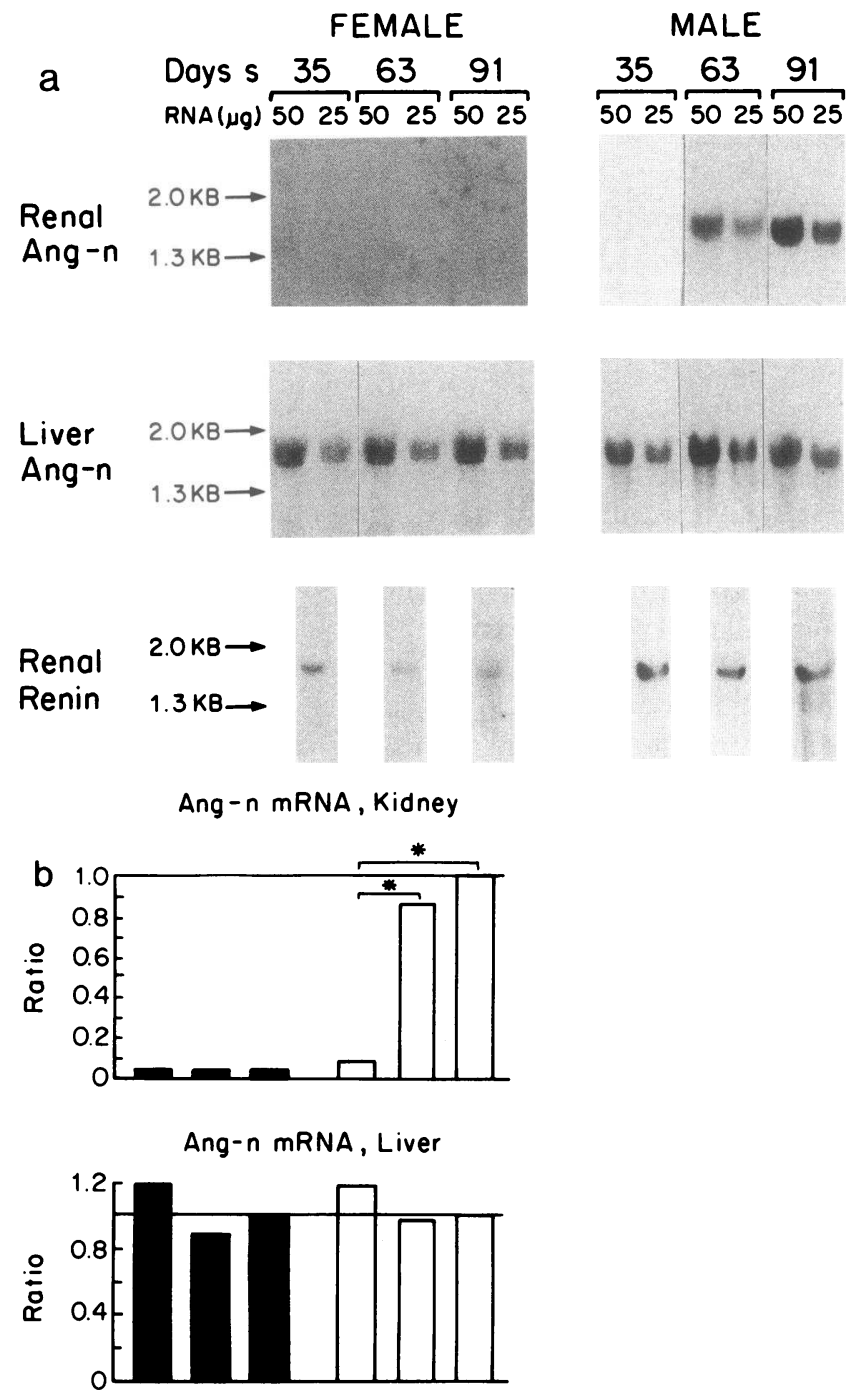

Renin mRNA, Kidney

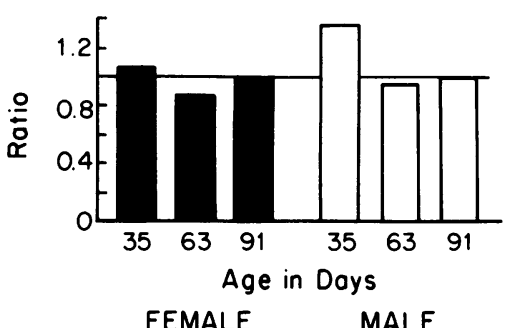

Figure 2. (a) Representative Northern analyses revealing influence of ontogeny on angiotensinogen (ang-n) and renin mRNA levels. Male or female rats were studied at days 35 (prepubertal), day 63 (pubertal), and day 91 (postpubertal). Several levels of total RNA were applied to gels at each age studied. The top panel demonstrates renal angiotensinogen mRNA levels during ontogeny in male and female rats, respectively. Note that male kidney ang-n mRNA levels increase dramatically with puberty, whereas female kidney ang-n mRNA levels are low and remain so. The middle panel shows high levels of liver angiotensinogen renin mRNA throughout ontogeny in both males and females. The lower panel ( $25 \mu \mathrm{g}$ total RNA/sample) demonstrates high renal renin MRNA levels throughout ontogeny in both males and females. (b) Densitometric analyses of slot blots of total RNA from kidneys hybridized to ang-n or to renin cDNA. Slopes were generated by applying three levels of RNA to slot blots, which were subsequently hybridized to the probes of interest. Units ence by sex hormones on the quantity of cellular autophagy in the proximal tubular cell (18). Castration increased cellular autophagy and catabolism, while administration of estradiol reduced autophagy (18). In yet other studies Maunsbach et al. found sexual dimorphism in the lysosomal pattern in three different segments of proximal tubule (20). Maunsbach et al. reported an increased number of lysosomes accompanied by a decline in the amount of reaction product of lysosomal ATP and $\beta$-glucuronidase after castration (21). Taken together, the above studies suggest that castration leads to a general reduction of the proximal renal tubular cell metabolism accompanied by an increase in cellular autophagy with catabolism predominating.

The renotropic effect of androgen is of particular interest with regard to the $\mathrm{Na}^{+}-\mathrm{H}^{+}$exchanger. The $\mathrm{Na}^{+}-\mathrm{H}^{+}$exchanger is a major mechanism responsible for $\mathrm{H}^{+}$secretion and $\mathrm{HCO}_{3}^{-}$-resorption in the proximal tubule. Mackovic et al. have shown sex differences in the rates of $\mathrm{Na}^{+}-\mathrm{H}^{+}$exchange in the mouse kidney (21). In their experiments, testosterone was found to increase the rate of exchange by more than $100 \%$, while castration of the male mouse decreased $\mathrm{Na}^{+}-\mathrm{H}^{+}$exchange. $\mathrm{Na}^{+}$dependent $\mathrm{D}$-glucose transport in mouse renal tubular luminal membranes also exhibited sex difference due to the stimulatory effect of testosterone. Since the present data suggest that androgen may also stimulate renal angiotensinogen mRNA expression and since angiotensin stimulates renal $\mathrm{Na}^{+}-\mathrm{H}^{+}$exchange (22), these findings raise the intriguing possibility that the $\mathrm{Na}^{+}-\mathrm{H}^{+}$exchanger may be influenced by androgen regulated angiotensin expression or the interaction of these two hormones. Our recent in situ hybridization study demonstrates that angiotensinogen mRNA is localized in the proximal tubular cell (5). The proximal convoluted tubule contains angiotensin-converting enzyme as well as Ang I and Ang II receptors. Filtered and reabsorbed renin within tubular cells may therefore generate angiotensin II locally. Liu and Cogan observed that alterations in angiotensin II activity can greatly alter bicarbonate absorption in the early proximal tubule (22). It may be that the androgen stimulation of the $\mathrm{Na}^{+}-\mathrm{H}^{+}$antiporter is mediated via the local production of angiotensin, a possibility that will require direct measurement.

Yet in studies by Mackovic et al. sex differences in $\mathrm{Na}^{+}-\mathrm{H}^{+}$ exchanger were not observed in the rat, nor did exchange rates increase with testosterone treatment (20). However, as noted above, these investigators did find differences in the rate of $\mathrm{Na}^{+}-\mathrm{H}^{+}$exchange in the mouse (20). Their observations in the rat could be due to an insufficient duration of testosterone replacement. They administered daily intramuscular injections of testosterone for $8 \mathrm{~d}$ (20) which might not be sufficiently long for induction of increased gene expression. The level of estrogen and the phase of estrus may also play a role in protein synthesis and therefore may obscure or emphasize di-

are arbitrary densitometric units. Ratio of slopes, i.e., day $x /$ day 91 were used for statistics. For use of representation, standard error bars were omitted. These were \pm 0.08 to 0.12 in all cases, except were zero when day 91 was compared to itself. Student $t$ tests of log ratio observed to expected were run, where $\log 1=0$ (see Methods). The top panel shows renal ang-n, and significant increase at puberty in the male is seen. In contrast, very low levels of renal ang-n mRNA are seen throughout ontogeny in the female. The middle panel shows tracings of liver angiotensinogen mRNA in during development (NS). The lower panel shows renal renin mRNA during development. 
Table II. Plasma Renin Concentration and Plasma Substrate Concentration

\begin{tabular}{lccccc}
\hline & Day 35 & Day 63 & Day 91 & Castrate & Testosterone \\
\hline Male & & & & & \\
PRC (ng AI/ml per h) & $4.0 \pm 4$ & $6.2 \pm 6$ & $3.0 \pm 0.8$ & $4.8 \pm 0.1$ & $4.5 \pm 0.2^{*}$ \\
PSC (ng AI/ml) & $316 \pm 39.8$ & $453 \pm 33.5$ & $415.9 \pm 15.4$ & $425 \pm 21.3$ & $430 \pm 16.3^{*}$ \\
Female & & & & $4.2 \pm 0.2^{\ddagger}$ \\
PRC (ng AI/ml per h) & $4.1 \pm 3$ & $5.1 \pm 0.6$ & $4.0 \pm 0.6$ & $412 \pm 15.3^{\ddagger}$ \\
PSC (ng AI/ml) & $340.1 \pm 41.8$ & $402 \pm 30.1$ & $410 \pm 16.1$ & \\
\hline
\end{tabular}

ND, not done. * Testosterone replacement in castrated male WKY. ${ }^{\ddagger}$ Testosterone administration to normal female WKY. NB: None of the parameters differed significantly.

morphism. For this reason testosterone replacement studies to castrated males provide a more reliable indicator of androgen synthesis induction. Testosterone treatment in our studies were performed over $20 \mathrm{~d}$ and clearly induced significant increases in renal angiotensinogen synthesis in both female and castrated male WKY rats.

Tissue specific regulation of renin and angiotensinogen have been demonstrated by previous studies $(4,23,24)$. We have observed that renin levels in submandibular gland, heart, testis, and adrenal increase at puberty but not renal renin mRNA. That the levels of renin in these tissues parallel those of androgen, estrogen or gonadotropic hormone suggests that the local renin-angiotensin system may be hormonally influenced. Conversely, the tissue renin-angiotensin system could play an important role in mediating or modulating these hormone functions.

\section{Acknowledgments}

We thank Ms Donna MacDonald and Ms Nancy Beattie for help in preparing this manuscript.

This work was supported by National Institutes of Health (NIH) grants HL-35610, HL-35792, HL-19259, HL-35252, NIH Specialized Center for Research in Hypertension HL-33697, and The Children's Renal Research Foundation.

\section{References}

1. Dzau, V. J., K. E. Ellison, T. Brody, J. Ingelfinger, and R. E. Pratt. 1987. A comparative study of the distribution of renin and angiotensin messenger riboneucleic acid in rat and mouse tissues. Endocrinology. 120:6:2334-2338.

2. Campbell, D. J. 1985. The site of angiotensin production. $J$. Hypertens. 3:199-207.

3. Dzau, V. J. 1986. Significance of the vascular renin-angiotensin pathway. (Editorial.) Hypertension. 8:553-559.

4. Ingelfinger, J. R., R. E. Pratt, K. E. Ellison, and V. J. Dzau. 1986. Sodium regulation of angiotensinogen mRNA expression in rat kidney cortex and medulla. J. Clin. Invest. 78:1311-1315.

5. Ingelfinger, J., E. A. Fon, K. E. Ellison, and V. J. Dzau. 1988. Localization of the intrarenal renin angiotensin system (RAS) by in situ hybridization of renin and angiotensinogen (ang-n) mRNA's. Kidney Int. 33:269.

6. Glisin, V., R. Crkvenjakov, and C. Byus. 1974. Ribonucleic acid isolation by cesium chloride centifugation. Biochemistry. 13:26332637.

7. Ullrich, A. J., J. Shine, J. Chirgwin, R. Pictet, E. Tischer, W. J. Rutter, and H. M. Goodman. 1977. Rat insulin genes: construction of plasmids containing the coding sequence. Science (Wash. DC). 196:1313-1319.
8. Campbell, D. J., and J. Habener. 1986. Angiotensinogen gene is expressed and differentially regulated in multiple tissues of the rat. $J$. Clin. Invest. 78:31-39.

9. White, B. A., and F. C. Bancroft. 1982. Cytoplasmic dot hybridization. J. Biol. Chem. 257:8569-8572.

10. Lynch, K. R., E. T. Simnad, E. T. Ben-Ari, and J. C. Garrison. 1986. Localization of preangiotensinogen messenger RNA sequences in the rat brain. Hypertension. 8:540-543.

11. Burnham, C. E., C. L. Hawelu-Johnson, B. M. Frank, and K. R. Lynch. 1987. Molecular cloning of rat renin cDNA and its gene. Proc. Natl. Acad. Sci. USA. 84:5605-5609.

12. Field, L. J., R. A. McGowan, D. P. Dickinson, and K. W. Gross. 1984. Tissue gene specificity of mouse renin expression. $\mathrm{Hy}$ pertension. 6:597-603.

13. Haber, E., T. Koerner, L. B. Page, B. Kilman, and A. Purnode. 1969. Application of radioimmunoassay for angiotensin I to the physiologic measurement of plasma renin activity in normal human subject. J. Clin. Endocrinol. Metab. 29:1349-1355.

14. Bradford, M. M. 1976. A rapid and sensitive method for the quantitation of microgram quantities of protein utilizing the principle of protein dye binding. Anal. Biochem. 72:248-254.

15. Hermann, H. C., and V. J. Dzau. 1983. The feedback regulation of angiotensinogen production by components of the renin-angiotensin system. Circ. Res. 52:328-334.

16. Granoff, A. B., and Abraham, G. E. 1979. Peripheral and adrenal venous levels of steroids in a patient with virilizing adrenal adenoma. Obstet. Gynecol. 53:111.

17. Watson, G., R. A. Davey, C. Labarca, and K. Paigen. 1981. Genetic determination of kinetic parameters in B-glucuronidase induction by androgen. J. Biol. Chem. 236:3005-3011.

18. Schiebler, T. H., and K. G. Danner. 1978. The effect of sex hormones on the proximal tubules in the rat kidney. Cell Tissue Res. 192:527-549.

19. Swank, R. T., K. Paigen, R. Davey, V. Chapman, C. Labarca, G. Watson, R. Garschow, E. J. Brandt, and E. Novak. 1973. Genetic regulation of mammalian glucuronidase. Rec. Prog. Hormone $R e-$ search. 34:401-436.

20. Mackovic, M., Z. Zimolo, G. Burckhardt, and I. Sabolic. 1986. Isolation of renal brush-border membrane vesicles by a low-speed centrifugation; effect of sex hormones on $\mathrm{Na}^{+}-\mathrm{H}^{+}$exchange in rat and mouse kidney. Biochim. Biophys. Acta. 862:141-152.

21. Maunsbach, A. B. 1966. Observations on the ultrastructure and acid phosphatase activity of the cytoplasmic bodies in rat kidney proximal tubule cells. J. Ultrastruct. Res. 16:197-238.

22. Liu, F.-Y., and M. G. Cogan. 1987. Angiotensin II: a potent regulator of acidification in the rat early proximal convoluted tubule. J. Clin. Invest. 80:272-275.

23. Dzau, V. J., T. Brody, K. E. Ellison, R. E. Pratt, and J. R. Ingelfinger. 1987. Tissue specific regulation of the renin angiotensin system. Hypertension. 9:III-36-III-41.

24. Ingelfinger, J. R., R. E. Pratt, and V. J. Dzau. 1988. Regulation of extrarenal renin during ontogeny. Endocrinology. 122:782-786. 